\title{
CONTEMPORARY DEVELOPMENT OF CREATIVE INDUSTRIES IN BOSNIA AND HERZEGOVINA
}

\author{
RAHMAN NURKOVIĆ \\ Department of Geography, Faculty of Science, University in Sarajevo, Bosnia and Herzegovina
}

Manuscript received: September 8, 2014

Revised version: February 27, 2015

\begin{abstract}
NuRкоvić R., 2015. Contemporary development of creative industries in Bosnia and Herzegovina. Quaestiones Geographicae 34(2), Bogucki Wydawnictwo Naukowe, Poznań, pp. 45-51, 2 figs, 1 table. DOI 10.1515/quageo-2015-0014, ISSN 0137-477X.

AвSTRACT: The article consists of three basic parts. In the first, the concept of post-socialist urban settlements and the position of creative industries in them are presented. In the second, examples of the development of creative actions of cities are given. In the third, the role of local policy in the development of new creative industries in Bosnia and Herzegovina is critically analysed, emphasising some of its shortcomings and drawing up recommendations for future policy measures. In Bosnia and Herzegovina, contemporary ideas of the development of the creative industries started to develop at the end of 2001 with the use of the technology of the developed countries of the world.
\end{abstract}

KEY WORDS: creative industries, economic growth, Bosnia and Herzegovina

Rahman Nurković, University in Sarajevo, Faculty of Science, Department of Geography, Zmaja od Bosne 35, 71000 Sarajevo, Bosnia and Herzegovina; e-mail: rahmannurkovic@hotmail.com

\section{Introduction}

Creative industries in Bosnia and Herzegovina, contrary to their low market dimension, have an economic potential which shows significant results in comparison with other segments of the economy. Their advantage in this country is the abundance of intellectual capital (Alexandersson 1967). During the past decade, Bosnia and Herzegovina cinematography developed into a modern, diversified sector, capable of producing high-quality audiovisual contents for the domestic and the foreign audience. It has scored the highest world awards for domestic feature-length films such as the Golden Bear at the Berlin International Film Festival, the Critics' Week Grand Prix at Cannes and the Golden Tiger of the Rotterdam Film Festival (Hesmondhalgh 2002). The film industry in Bosnia and Herzegovina is capa- ble of creating new jobs and producing different economic benefits, thus contributing to general social and economic cohesion, at the same time being a key medium for the transfer and development of cultural values. Its contribution is about $40 \%$, which is $8.3 \%$ above the average for the economy.

The concentration of intellectual capital is particularly high in the video industry, IT, multimedia, advertising, etc. Resources and possibilities in the domain of the development of creative clusters or art incubators in regional centres are especially promising in the towns of Bihać, Mostar, Sarajevo and Tuzla. The resources of creative industries at the level of Bosnia and Herzegovina as well as their infrastructure embrace 3,836 enterprises, which is about $14.7 \%$ of their total number. About $24 \%$ of them concentrate in the area of literary creation and about $30 \%$ in archi- 
tecture, their lowest proportion being in the area of music creation and production, at a mere $1.4 \%$. There are 96 cultural events of international importance per annum, of which almost $50 \%$ in creative industries (in the publishing industry, 27; in the film industry, 17; and in the music industry, 15). With the creation of new jobs in the creative industries, poverty is reduced, participation in commercial exchange is achieved, the development of new technologies is induced, and the general quality of living of the Bosnia and Herzegovina population improves (Centre for Policy and Governance 2013).

\section{Methods of work and data sources}

The methodological approach was adjusted to the purpose of the paper, i.e. the contemporary development of the creative industries in Bosnia and Herzegovina. Studies of the creative industry in the local and regional areas of Bosnia and Herzegovina were included. In the estimation of the economic contribution of the development of new creative industries, almost exclusively quantitative methods were used, ranging from stochastic to deterministic. The data were obtained from publications of studies of this topic, from the author's own previous researches on the creative industries, and the statistical documentation of the Agency for Statistics of Bosnia and Herzegovina (Nurković 2001). About twenty economic activities were examined. An evaluation of the direct impact of the creative industries on the local and regional development of the economy in Bosnia and Herzegovina is a good basis for defining and applying models that offer an insight into the overall development of those industries there. However, this article is devoted to quite a challenging area of human activity which has not been explored in Bosnia and Herzegovina so far.

\section{General characteristics of the post- socialist development of the creative industries in Bosnia and Herzegovina}

A sudden change in the political and social system of Bosnia and Herzegovina at the beginning of the 1990s happened at a critical moment in the region's development. The research on the creative sector in Bosnia and Herzegovina involving its mapping and formulation of indicators has been conducted with the participation of cities and urban organisations under the European Union programme of E761 Convergence since 2004. It mostly embraces the gathering and processing of the available statistical data on creative business industries as well as data obtained directly through questionnaires from registered economic entities.

This partner programme on the creative industries is financed by the European Union within the cross-border development in Bosnia and Herzegovina, with an aim of opening the door to research on and the promotion of values of the creative sector and a knowledge-based economy, thus strengthening the capacities of the creative sector through the support and initiatives of young people. The increase in the importance of knowledge in Bosnia and Herzegovina, especially innovative knowledge, is largely connected with globalisation processes. The introduction of innovations to the economy, primarily through the creation and use of information and communication technologies (ICT), has intensified globalisation processes even more (Nurković 2006).

Today, global-range communication in the world has become much easier. There are a number of studies that show the development of creative industries in the world (Oinas, Lagendijk 2005). However, in the global economy cities will compete among themselves. The ease with which people and capital can move makes each city strive to attract and keep as many 'valuable' residents, workers, visitors and investments as possible, particularly those whose activity is innovation-oriented, i.e. associated with a high level of knowledge intensity and creativity. In Bosnia and Herzegovina this area includes the creative cities of Tuzla, Banja Luka, Sarajevo, Mostar, and Zenica (Fig. 1).

The Bosnia and Herzegovina cities have adjusted to changes that have occurred in social and economic development. The ability to take advantage of the new opportunities created by those changes is an exercise in creativity. Adaptiveness also implies openness to novelty and innovations. According to Hospers (2003), there are three other characteristics that boost the chances of the appearance of creativity, which in turn enhances the development of the knowledge-based 


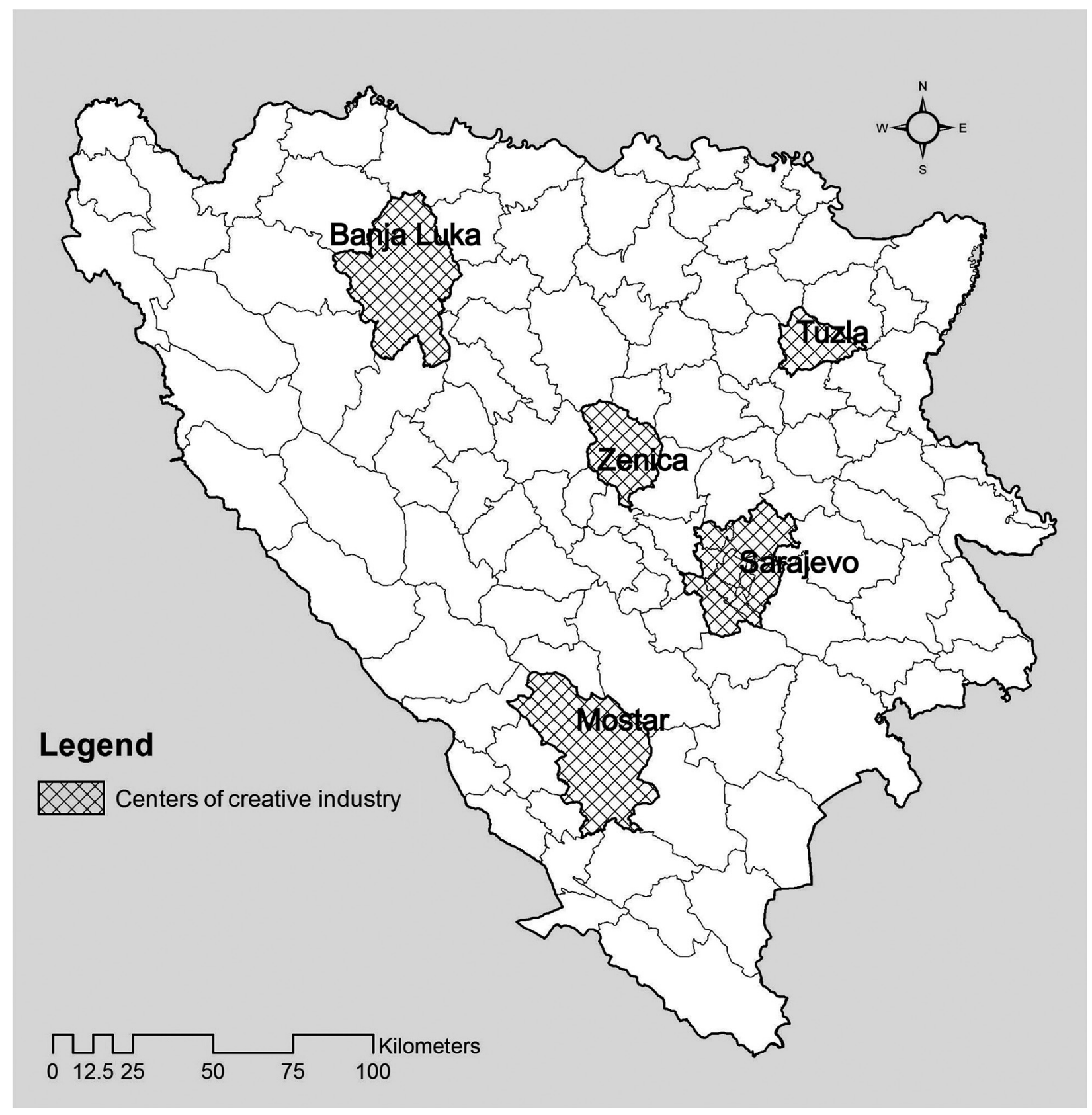

Fig. 1. Centres of the creative industries in Bosnia and Herzegovina, 2011. Author: R. Nurković.

economy in a city. These are concentration, diversity, and instability. Urban creativity is mostly stimulated by the presence of a specified number of people in a specific area.

This concentration of people in cities creates conditions favourable to a faster development of communication and interactions. From an economic point of view, in Bosnia and Herzegovina cities the most important is the diversity of the economic structure, not only regarding the labour market (availability of workers and a variety of skills), but also the types of activity conducted.
It is usually assumed that diversity is associated with the size of a city. However, several studies have shown the impossibility of defining unambiguously any relationship between the size of a city and the diversity of its economic structure (Davies, Donoghue 1993).

Another important aspect of the research on urban creativity in Bosnia and Herzegovina is the determination of a city's economic base (Landry 2002). Is its development connected, first of all, with a system of production or with consumption opportunities? So far it has been the prevail- 
ing opinion that production is the main driver of urban growth, and that the cities of Tuzla, Zenica, Mostar and Sarajevo as production centres generate wealth precisely because they produce specified products at a large scale. Each city has a chance to be 'creative', but not all of them become so. An indispensable condition is urban creativity that includes creative actions and a creative environment. However, this is not a sufficient condition. Sometimes we must help the city become creative through a policy that aims to improve its environment or initiate creative actions. The policy often leads to the development of local and regional business support for infrastructure that plays a key role in the growth of the creative and cultural industries in the city (Haase, Vaishar, Węcławowicz 2011).

\section{Characteristics of the labour force in the creative industries of Bosnia and Herzegovina}

At the time when man is being replaced by sophisticated technologies, creative industries affirm human capital in Bosnia and Herzegovina. Contemporary knowledge is very complex and specific requirements are necessary for its development, first of all, specialised staff, high technology, and investment in the creative industries (Chapain, De Propris 2009). Those industries have played a significant role in the systemic transformation of Bosnia and Herzegovina cities. The sector of creative industries is extremely heterogeneous, therefore it can hardly be characterised precisely as a whole. Such a broader perspective on the systemic change, not only from the point of view of the main urban centres, enables a more detailed insight into the role of the creative sector in the transformation of urban areas in Bosnia and Herzegovina.

The labour force is undoubtedly an extremely mobile location factor which followed the creative industries and caused the biggest population movements in Bosnia and Herzegovina. Specific creative branches have different requirements with regard to the quantitative and qualitative characteristics of the labour force (Scott 2004).

So, the labour force in the creative branches of industry was a basis for intense development of all activities in Bosnia and Herzegovina. In 2011, the creative sector accounted for 3,581 of the country's total active employed population. Architecture made up $29.7 \%$, publishing industry, $24.3 \%$, advertising, $19.7 \%$, the fashion industry, $5.6 \%$, music production, $4.5 \%$, radio and television, $4.4 \%$, film and cinematography, $2.8 \%$, culture and art, $2.6 \%$, and video and multimedia, $1.6 \%$ (Table 1, Fig. 2).

The discharge of the labour force in other activities was considerably faster than the creation of new jobs in the creative industries, which caused economic migrations of the population in urban centres. There has been a permanent increase in the active population in the creative sector of Bosnia and Herzegovina (Nurković 2011). The largest part of the active population is employed in the creative branches of industry and in tertiary activities.

An entrepreneurial or business approach to creativity in Bosnia and Herzegovina is at the incubation stage, and is often frozen due to complex state administration, so there has been little research on the cultural and creative sector,

Table 1. Branches of the creative industry in Bosnia and Herzegovina, 2011.

\begin{tabular}{|l|c|c|}
\hline \multicolumn{1}{|c|}{ Branches } & Number of registered enterprises & Share in total number of creative industries \\
\hline Literary creation and publishing & 873 & $24.38 \%$ \\
\hline Musical creativity and production & 162 & $4.52 \%$ \\
\hline Video and multimedia industry & 57 & $1.60 \%$ \\
\hline Advertising & 708 & $19.77 \%$ \\
\hline Architecture & 1,065 & $29.74 \%$ \\
\hline Filmmaking and cinematography & 103 & $2.88 \%$ \\
\hline Radio and television & 158 & $4.41 \%$ \\
\hline Entertainment and leisure & 158 & $4.41 \%$ \\
\hline Cultural heritage & 96 & $2.68 \%$ \\
\hline Fashion industry & 201 & $5.61 \%$ \\
\hline Total & 3,581 & $100.00 \%$ \\
\hline
\end{tabular}

Source: adapted from the Centre for Policy and Governance; Foreign Trade Chamber of Bosnia and Herzegovina, 2013. 
Share in total number of creative industries (\%)

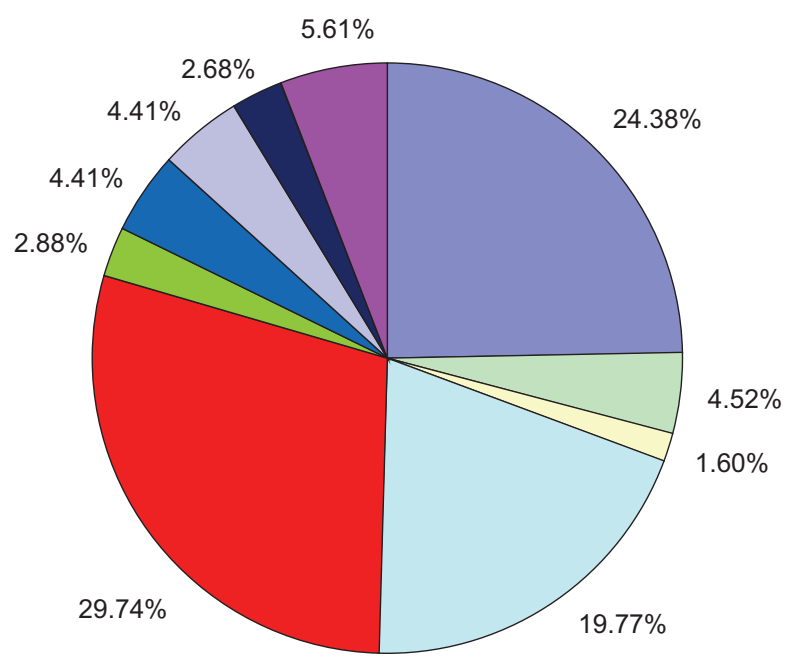

Literary creation and publishing
Musical creativity and production
Video and multimedia industry
Advertising
Architecture
Filmmaking and cinematography
Radio and television activities
Entertainment and Leisure
Cultural heritage
The fashion industry

Fig. 2. Share in the total number of creative industries in Bosnia and Herzegovina, 2011. Source: adapted from the Centre for Policy and Governance, 2013.

and there is no base of its mainstays. Therefore, a methodological approach for the mapping and preliminary description of the four urban centres in Bosnia and Herzegovina was provided by an experienced partner from the European Union (Davies, Donoghue 1993).

The results presented in this article should be understood exclusively as ones in the creative sectors of the cities of Tuzla, Banja Luka, Mostar and Sarajevo. Such creativity, enriched by a business approach and free of traditional sluggishness, enables young people better expression and opens new doors to the European market of creative industries. The findings of this study could be a basis for future researchers and similar non-profit initiatives in further work on the development of the creative sector in the cities of Bosnia and Herzegovina. A relatively small number of studies have been devoted to the place and role of the creative sector in this process. However, it should be emphasised that the regional urban centres in Bosnia and Herzegovina entered their creative path later than those in Western Europe, such as infrastructure development or public transport.

\section{Role of the local policy in the development of new creative industries}

There are a growing number of examples indicating the significance of the local initiative for the development of culture, and for the improvement of the economic and social attractiveness of European cities. Cities like Tuzla, Banja Luka, Sarajevo, Mostar and Zenica are known for such a cultural policy oriented toward infrastructure development which should support small and new business ventures in the field of culture, i.e. the creative sector, such as design, music, digital media and television. Such a policy in Bosnia and Herzegovina implies the establishment of forums for the creative sector within which the needs of various creative industries for financial support will be identified. The next step is the creation of capital funds for business ventures supported by local authorities whose purpose is to improve the promotion of products and services generated in the creative sector (Chapain, De Propris 2009).

Other strategies involve investment in laboratories of digital media, the organisation of fairs at which new design developments are presented, sales of specific products or services, and support for business development or business education of the population in Bosnia and Herzegovina. This kind of local policy is described as a strategy of culture production and is based on an economic approach. In Bosnia and Herzegovina, the role of the creative sector in the development policies of municipalities and cities can be described as extremely passive (Nurković 2012). The Municipality of Tuzla stands out as a specific and positive example, although interlocutors say that the significance of the creative sector in Tuzla has 
been recognised only formally, and that concrete activities have not started yet except for financing and co-financing of manifestations. The Municipality of Tuzla recognised the importance of the role of the creative sector in city development already six years ago. In 2007, it implemented a project together with the British Council: the Tuzla Creative Industry Project. The main objective of the local policy in Bosnia and Herzegovina is to support the development of creative industries.

The UK South East Forum project is a regional programme of the British Council jointly organised by its offices in Albania, Bosnia and Herzegovina, Bulgaria, Croatia, Kosovo, Macedonia, Romania, Serbia, Montenegro, and the United Kingdom. Under the programme UK SEE Forum - Creative Industries, the British Council has promoted and developed the creative industry in the countries of south-eastern Europe as a continuation of the started programmes and also in other countries of the world with an open concept adequate to the conditions obtaining in those countries.

The programme in south-eastern Europe aimed at exploiting the potential and resources of local cultural and economic milieux on the example of selected cities. Those were: Tuzla, Podgorica, Split, Novi Sad, Priština, Plovdiv, Jaš, and Tirana. Tuzla was chosen as an example of a creative city in Bosnia and Herzegovina (Scott 2004). At the moment, there is no single governmental institution dealing with the development of the creative industries, except the Centre for Policies and Management in Sarajevo. Non-adjustment of public attitudes and the non-existence of a consensus regarding the role and future development of the creative industries in Bosnia and Herzegovina is only one more element that causes autarchic and elemental actions at all levels of government in Bosnia and Herzegovina. In this sense, the approach to the creative industries must be oriented towards long-term sustainability, taking into consideration all conditions contributing to the creation of a common communication language and the establishment of an equal dialogue between sectors characterised by a surplus of financial resources and those possessing creative skills and talents (Landry 2002).

The beginning of the $21^{\text {st }}$ century marks a breakthrough in the urban and metropolitan policies of post-socialist cities in terms of activities designed to enhance the competitiveness of their entire metropolitan areas, increase their structural and spatial cohesion, and develop modern economic sectors and creative social initiatives. The present-day development philosophy of the post-socialist cities encompasses elements of the growth of the creative sector, a knowledge-based economy, and innovative sectors relying on highly qualified human capital and advanced technologies (Stryjakiewicz, Męczyński, Stachowiak 2014).

\section{Conclusions}

Over the past two decades Bosnia and Herzegovina has witnessed a wide-ranging transformation in many aspects. The introduction of a market-oriented economy after half a century of socialism has brought about deep social, economic, cultural and political changes. Hence our contribution aims to explore the role of creativity and creative industries in the post-socialist urban settlements of Bosnia and Herzegovina. Creative industries played a significant role in the systemic transformation of its cities. The sector of creative industries is extremely heterogeneous here, it is therefore difficult to characterise it precisely as a whole. Cities in Bosnia and Herzegovina have adjusted to changes occurring in social and economic development (Nurković 2010). The ability to take advantage of the new opportunities created by those changes is an exercise in creativity. Urban creativity is mostly stimulated by the presence of a specified number of people in a specific area. The concentration of people in Bosnia and Herzegovina cities has created conditions favourable to a faster development of the creative industries.

There are a number of examples indicating the significance of the local initiative for the development of culture and the fostering of the economic and social attractiveness of European cities. Cities like Tuzla, Banja Luka, Sarajevo, Mostar and Zenica are famous for cultural policies oriented towards the construction of infrastructure supporting small and new business ventures in the field of culture, i.e. the creative sector, such as design, music, digital media and television. Such a policy implies the establishment of forums for the creative sector on which the needs of vari- 
ous creative industries for financial support will be identified. The entrepreneurial business approach to creativity in Bosnia and Herzegovina is at the incubation stage, and is often frozen due to complex state administration, so there have been little research on the cultural / creative sector, and there is no base containing its main bearers.

\section{References}

Alexandersson G., 1967. Geography of manufacturing. Prentice Hall, Englewood Cliffs, N.J.

Centre for Policy and Governance. cpu.org.ba, Sarajevo.

Chapain C., De Propris L., 2009. Drivers and processes of creative industries in cities and regions. Creative Industries Journal 2 (1): 9-18.

Davies W.K.D., Donoghue D.P., 1993. Economic diversification and group stability in an urban system: The case of Canada, 1951-86. Urban Studies 30 (7): 1165-1186.

Foreign Trade Chamber of Bosnia and Herzegovina 2013. Registry of Economic Subjects. Sarajevo.

Haase A., Vaishar V., Węcławowicz G. 2011. The post-socialist condition and beyond: Framing and explaining urban change in East-Central Europe. In: Haase A., Steinführer A., Kabisch S., Grossmann K., Hall R. (eds), Residential change and demographic challenge: The inner city of East Central Europe in the 21 $2{ }^{\text {st }}$ century. Ashgate, Aldershot: 63-84.

Hesmondhalgh D., 2002. The cultural industries. SAGE Publications, London.
Hospers G.J., 2003. Creative cities: Breeding places in the knowledge economy. Knowledge, Technology and Policy 16 (3): 143-162.

Landry C., 2002. Cultural policy in Bosnia and Herzegovina: Expert report. MOSAIC PROJECT, Council of Europe.

Nurković R., 2001. Vpliv industrije na razvoj Tuzlanske kotline (Effect of industry on the development of the Tuzla Valley). Doctoral thesis, Ljubljana.

Nurković R., 2006. Ekonomska geografija svijeta (Economic geography of the world). University of Tuzla, Faculty of Science, Tuzla.

Nurković R., 2010. Influence of tertiary activities on transformation of the rural settlements in Bosnia and Herzegovina. Journal for Geography 5 (1). Special Issue for the 17th Annual Colloquium of the IGU Commission on the Sustainability of Rural Systems, 2009: 67-74.

Nurković R., 2011. Contemporary spatial and hierarchic characteristics of urban system of Bosnia and Herzegovina. 16th International Conference on Urban Planning, Regional Development and Information Society, REAL CORP 2011, Essen.

Nurković R., 2012. Urbana geografija svijeta (Urban geography of the world). University of Sarajevo, Faculty of Science, Sarajevo.

Oinas P., Lagendijk A., 2005. Proximity, distance and diversity: Issues on economic interaction and local development. Ashgate, Aldershot.

Scott A.J., 2004. Cultural-products industries and urban economic development: Prospects for growth and market contestation in global context. Urban Affairs Review 39 (4): 461-490.

Stryjakiewicz T., Męczyński M., Stachowiak K., 2014. Role of creative industries in the post-socialist urban transformation. Quaestiones Geographicae 33 (2): 19-35. 